\title{
Situação nutricional e alimentar de pré-escolares no semi-árido da Bahia (Brasil): II - Hipovitaminose A*
}

\section{Nutritional status of pre-school children of the semi-arid region of Bahia (Brazil): II - Vitamin A deficiency}

\author{
Leonor M.P. Santos, Ana Marlucia O. Assis, Maisa C. Martins, Maria P.N. Araújo, Saul S. \\ Morris e Mauricio L. Barreto \\ Escola de Nutrição, Universidade Federal da Bahia. Salvador, BA- Brasil (L.M.P.S.; A.M.O.A.; \\ M.C.M.; M.P.N.A.); Maternal and Child Epidemiology Unit, Department of Epidemiology and \\ Population Sciences. London School of Hygiene and Tropical Medicine (S.S.M.); Instituto de Saúde \\ Coletiva, Universidade Federal da Bahia. Salvador, BA- Brasil (M.L.B.)
}

\begin{abstract}
Resumo
Foram estudados 754 pré-escolares de áreas urbanas de sete municípios do semiárido do Estado Bahia, Brasil, com o objetivo de determinar a prevalência da hipovitaminose A e sua associação com a idade, sexo, renda em salário-mínimo, escolaridade materna e adequação dietética em vitamina A. Na amostra estudada não se registrou nenhum caso de sinais e/ou sintomas de xeroftalmia durante $o$ exame clínico-oftalmológico. Em 563 crianças foi possível a coleta de sangue para determinação de retinol sérico; encontrou-se um valor médio de $20,3 \mu \mathrm{g} /$ $\mathrm{dl}(\mathrm{DP}=10,8 \mu \mathrm{g} / \mathrm{dl})$ e uma prevalência de $15,3 \%$ de níveis deficientes (abaixo de $10,0 \mu \mathrm{g} / \mathrm{dl}$ ). Em todos os sete municípios estudados a prevalência de retinol sérico deficiente foi superior a 5,0\% que é nível crítico proposto pela OMS para considerar a hipovitaminose A como problema de saúde pública. A distribuição de retinol sérico encontrada não teve relação com o sexo das crianças, mas com a idade, diminuindo a prevalência de níveis deficientes e baixos na medida em que a idade aumenta. Não se encontrou associação entre renda familiar per capita ou escolaridade materna e a prevalência de níveis de retinol deficiente. Os resultados de consumo alimentar provenientes do inquérito recordatório de $24 \mathrm{~h}$ mostraram que apenas $8 \%$ das crianças consumiram quantidades adequadas de retinol ou de seus precursores; $66 \%$ ingeriam abaixo da metade e quase $35 \%$ delas não chegaram a ingerir nem um quarto da quantidade recomendada para sua faixa etária. A carência de vitamina A deve ser considerada como problema de saúde pública severo, tanto pela alta prevalência de níveis deficientes de retinol em todos os municípios como também pela dimensão da inadequação dietética.
\end{abstract}

Deficiência de vitamina A, epidemiologia. Vitamina A, sangue. Inquérito sobre dietas.

\begin{abstract}
A survey of 754 preschool children was undertaken in the urban areas of seven small towns of the semi-arid region of Bahia, Northeastern Brazil, to determine the prevalence of vitamin A deficiency, as well as its association with variables
\end{abstract}

\footnotetext{
* Financiado pelo Projeto HOPE (Fortaleza), com recursos da USAID (Projeto 598.06-G-SS-7003-00).

Correspondência para/Correspondence to: Leonor M.P.Santos - Escola de Nutrição. Universidade Federal da Bahia. Rua Araújo Pinho, 32 - Canela

- 40110-150 - Salvador, BA - Brasil. Fax : (071) 245.0587 E-mail: leonor@ufba.br

Recebido em 5.9.1994. Reapresentado em 1.6.1995. Aprovado em 8.8.1995.
} 
such as a age, family income, mother's schooling and dietary adequacy in vitamin A. Protein energy malnutrition and anemia were also studied and are reported separately. The clinical ophthalmological examination did not reveal any signs or symptoms of xerophthalmia amongst these children. In 563 children serum retinol was determined and the average value found was $20.3 \mu \mathrm{g} / \mathrm{dl}(\mathrm{SD}=10.8$ $\mu \mathrm{g} / \mathrm{dl}$ ); the prevalence of deficient serum retinol (below $10.0 \mu \mathrm{g} / \mathrm{dl}$ ) was of $15.3 \%$. In all 7 localities studied, the prevalence of deficient retinol levels was above $5.0 \%$, the criterion recommended by WHO for considering it a Public Health Problem. The distribuition of serum retinol was similar between the sexes, but there was an age trend: the prevalence of deficient and low levels decreased with age. There was no association between deficient serum retinol and family income per capita or mother's education. Results from the 24 hood consumption survey revealed that only $8 \%$ of children had an adequate intake of vitamin $A$ through the diet; $66 \%$ received less than $1 / 2$ and $35 \%$ less than $1 / 4$ of the recommended daily intake of vitamin A. Vitamin A deficiency should be considered a Public Health Problem in the region due to the high prevalence of deficient levels of serum retinol as well as the large dietary inadequacy.

Vitamin A deficiency, epidemiology. Vitamin A, blood. Diet surveys.

\section{INTRODUÇÃO}

A deficiência de vitamina A afeta cerca de 50 milhões de crianças em países em desenvolvimento; esta carência nutricional pode ser considerada como problema de saúde pública em 37 países, incluindo o Brasil (região Nordeste) ${ }^{36}$. O papel fisiológico da vitamina A é bastante diversificado: no mecanismo visual tem função primordial já que faz parte da molécula dos pigmentos visuais responsáveis pela visão. No tecido epitelial, por mecanismos ainda não bem elucidados, mantém a integridade e a diferenciação de epitélios especializados ${ }^{25}$; um dos epitélios, severamente afetado nos casos de carência grave, é o do revestimento ocular, sendo a cegueira irreversível (xeroftalmia e ceratomalácia) uma das seqüelas graves ${ }^{35}$. Estudos em animais e humanos têm indicado que a deficiência de vitamina A pode também comprometer o sistema imunológico ${ }^{27}$.

Recentemente a necessidade de combater a deficiência de vitamina A ganhou uma nova dimensão. A análise agregada de diversos estudos de intervenção, randomizados e controlados, mostrou que a suplementação com vitamina A em crianças pré-escolares, em áreas onde a deficiência desta vitamina é endêmica, provoca uma redução média na mortalidade de $23 \%{ }^{4,12,19}$; existe alguma evidência de que isto se deve à redução da severidade da morbidade, notadamente da diarréia ${ }^{3,18}$.
Entre as décadas de 70 e 80 , vários estudos foram publicados sobre a deficiência desta vitamina em nível bioquímico, em Estados do Nordeste ${ }^{14,33}$. Em relação a dados de consumo alimentar, o Estudo Nacional de Despesa Familiar (ENDEF) ${ }^{15}$, realizado entre 1975-76, mostrou que 53\% das famílias, com crianças menores de cinco anos no Nordeste urbano e $69 \%$ das famílias no Nordeste rural, não consumiam sequer a metade da recomendação diária de vitamina A da FAO/OMS ${ }^{11}$. A ocorrência de cegueira nutricional por deficiência de vitamina A é mencionada na literatura brasileira desde o século passado $^{17}$ e persiste até nossos dias; uma análise histórica revela que neste século o problema tem se restringido primordialmente à região Nordeste, sobretudo durante os períodos de secas ${ }^{7,9,22}$. No início da década de 80 , novamente durante um período prolongado de seca, registraram-se no Estado da Paraíba e Rio Grande do Norte casos clínicos de carência de vitamina A e de cegueira nutricional $^{1,10,24,28,29}$. Em 1983 foi iniciado o Programa de Combate a Hipovitaminose A, pelo Instituto Nacional de Alimentação e Nutrição (INAN), através do qual megadoses de 200,000 UI de vitamina A são distribuídas a crianças de 1 a 5 anos durante as campanhas de vacinação de massa em vários Estados do Nordeste ${ }^{2,30,31}$.

Inexistem estudos populacionais sobre a prevalência da hipovitaminose A em pré-escolares 
no Estado da Bahia. O estudo de níveis de retinol hepático em material de necrópsias, realizado em Salvador, capital do Estado ${ }^{26}$ detectou baixas reservas de retinol no fígado de crianças que morreram por causas diversas. Estes resultados foram surpreendentes por tratar-se de uma das poucas cidades no Brasil onde o consumo de vitamina A supunha-se adequado devido a utilização do azeite de dendê, que faz parte do hábito alimentar da população. Devido a escassez de dados sobre hipovitaminose A, em nível estadual, o programa de intervenção com cápsulas de vitamina $\mathrm{A}$, citado acima, não foi implantado na Bahia.

O presente estudo teve como objetivo determinar a prevalência da hipovitaminose A numa população de pré-escolares do semi-árido baiano através de indicadores bioquímicos e dietéticos, além de analisar alguns de seus fatores determinantes.

\section{MATERIAL E MÉTODO}

\section{Amostragem, Coleta de Dados e Inquérito Dietético}

Na seleção da área e da amostra, foi empregada a mesma metodologia descrita no primeiro estudo desta série $^{32}$. Foram estudados 754 pré-escolares de 7 municípios do semi-árido da Bahia: Serrinha, Valente, Cansanção, Queimadas, Santa Luz, Retirolândia e Conceição do Coité, pela mesma equipe, no período de janeiro a junho de 1989. Durante as visitas domiciliares foi realizado inquérito dietético pelo método recordatório de $24 \mathrm{~h}^{35}$. Foi possível obter informações quantitativas sobre o consumo de vitamina A em 616 pré-escolares.

\section{Exame Clínico e Dosagem de Retinol Sérico}

Ao final da visita domiciliar as famílias eram convocadas a levar a criança em jejum ao Posto de Saúde, em data aprazada, onde eram realizados os exames clínico-oftalmológicos, com uma pequena lanterna e sem empregar corantes para detectar possíveis sinais clínicos de xeroftalmia. Também foram coletadas as medidas antropométricas ${ }^{32} \mathrm{e}$ a amostra de sangue por venipuntura; esta foi separada em duas alíquotas: uma de cerca de $0,25 \mathrm{ml}$ para a dosagem de hemoglobina e a alíquota restante ( 3 a $4 \mathrm{ml}$ ), armazenada em tubo de ensaio, no escuro, para separação do soro e posterior dosagem de retinol. Após 2 a 3 horas, sempre na semi-obscuridade, o sangue era centrifugado duas vezes em centrifuga FANEM Excelsa-Baby e o soro separado e congelado até a dosagem. Foi determinado o retinol sérico pelo método espectrofotométrico de Bessey-Lowry modificado ${ }^{5,20}$, no Laboratório de Bioquímica da Nutrição da Escola de Nutrição*, em Salvador, por duas técnicas em patologia clínica, devidamente treinadas. Para as leituras empregouse um espectrofotômetro UV/Visível Beckman DU4. O padrão utilizado foi o acetato de retinol (USP reference standard vitamin A, USP Inc. Rockville MD). As dosagens foram realizadas em duplicata sempre que o volume do soro assim o permitia (cerca de $70 \%$ das amostras); nas condições empregadas obteve-se coeficiente de variação intra-amostra de 5,2\%. Amostra de sangue, em quantidade suficiente para a dosagem de retinol, foi coletada de 563 pré-escolares dos sete municípios.

\section{Análise de Dados}

A análise quantitativa do consumo alimentar foi realizada com o Programa de Apoio à Decisão em Nutrição (versão 1), modificado pela introdução de alimentos regionais e pela atualização dos teores de vitamina A de alguns alimentos, a partir da tabela de composição de alimentos de ENDEF $^{16}$; considerou-se o teor de vitamina $\mathrm{A}$ em microgramas de retinol equivalente por $100 \mathrm{~g}$ de parte comestível. Para as análises estatísticas empregaram-se os programas SPSS-PC+ e EpiInfo. Para a interpretação dos níveis de retinol sérico, foram adotados os pontos de corte aceitos pela Organização Mundial da Saúde ${ }^{36,37}$, a saber:

\begin{tabular}{lcr} 
Categoria & \multicolumn{2}{c}{ Nível de retinol sérico } \\
& $\mu \mathrm{g} / \mathrm{dl}$ & $\mu \mathrm{mol} / \mathrm{l}$ \\
Deficiente & $<10,0$ & $<0,35$ \\
Baixo & $10,0-19,9$ & $0,35-0,69$ \\
Aceitável & $20,0-29,9$ & $0,70-1,04$ \\
& & \\
Normal & $\geq 30,0$ & $\geq 1,05$
\end{tabular}

O critério empregado até recentemente para considerar a hipovitaminose A como problema de saúde pública era o de prevalência de $5 \%$ ou mais de níveis deficientes de retinol em pré-escolares ${ }^{37}$. O novo critério, proposto pela OMS/ UNICEF, inclui somente as crianças maiores de 1 ano (devido a variabilidade do retinol sérico no $1^{\circ}$ ano de vida) e considera tanto níveis deficientes como baixos ${ }^{37}$ :

Problema de Prevalência de retinol $<0,70 \mu \mathrm{mol} / \mathrm{l}$

saúde pública em crianças maiores de um ano

$\begin{array}{lc}\text { Leve } & 2,0-10,0 \% \\ \text { Moderado } & 10,1-19,9 \% \\ \text { Severo } & \geq 20,0 \%\end{array}$




\section{RESULTADOS}

Nas 754 crianças examinadas no presente estudo não foram detectados sinais clínicos e/ou sintomas de xeroftalmia. Nos 563 pré-escolares com dosagem de retinol sérico encontrou-se uma média de $20,3 \mu \mathrm{g} /$ $\mathrm{dl}(\mathrm{DP}=10,8 \mu \mathrm{g} / \mathrm{dl})$, correspondendo a $0,71 \mu \mathrm{mol} / \mathrm{l}$ ( $\mathrm{DP}=0,38 \mu \mathrm{mol} / \mathrm{l}$ ); a distribuição de freqüência desses valores encontra-se na Figura 1. A Tabela 1 mostra a prevalência de níveis de retinol sérico por categoria, tanto na amostra toda $(\mathrm{N}=563)$, como também nos maiores de um ano $(\mathrm{N}=516)$; os resultados não diferem significativamente $(\mathrm{p}=0,989)$ e portanto em todas as outras análises considerou-se a amostra como um todo. Nesta população foram superados tanto o limite de 5\% de níveis deficientes como o de $20 \%$ de níveis deficientes e baixos. Em cada um dos municípios estudados os limites foram ultrapassados: nas crianças de Valente foi registrada a maior prevalência de retinol sérico deficiente $(31,9 \%)$ e nas de Serrinha, a menor $(7,8 \%)$.

A prevalência de níveis de retinol deficiente e baixo variou de modo significativo segundo a idade ( $\mathrm{p}=0,011$ e $\mathrm{p}=0,000$ respectivamente, teste para tendência) (Figura 2). O pico de prevalência de retinol sérico deficiente foi registrado na faixa de 24 a 35 meses $(22,9 \%)$ e a menor prevalência observada foi na faixa de 48 a 59 meses $(7,8 \%)$. Para níveis

Tabela 1 - Distribuição dos níveis séricos de retinol por categoria em pré-escolares do semi-árido da Bahia - 1989.

\begin{tabular}{lrrrrr}
\hline & & \multicolumn{2}{c}{ Crianças 0-72 meses } & \multicolumn{2}{c}{ Crianças 12-72 meses } \\
Categoria* & & $\mathrm{N}$ & Prevalência** $(\%)$ & $\mathrm{N}$ & Prevalência** $(\%)$ \\
\hline Deficiente $(<10,0 \mu \mathrm{g} / \mathrm{dl})$ & 86 & 15,3 & 78 & 15,1 & \\
Baixo $(10,0-19,9 \mu \mathrm{g} / \mathrm{dl})$ & 222 & 39,4 & 199 & 38,6 \\
Aceitável $(20,0-29,9 \mu \mathrm{g} / \mathrm{dl})$ & 83 & 14,7 & 77 & 14,9 & \\
Normal $(\approx 30,0 \mu \mathrm{g} / \mathrm{dl})$ & 172 & 30,6 & 162 & 31,4 & 100,0 \\
\hline Total & & 563 & 100,0 & 516 & \\
\hline
\end{tabular}

* Pontos de corte de acordo com a $\mathrm{OM} \mathrm{S}^{36,37}$

$* * p=0,989$

Freqüência

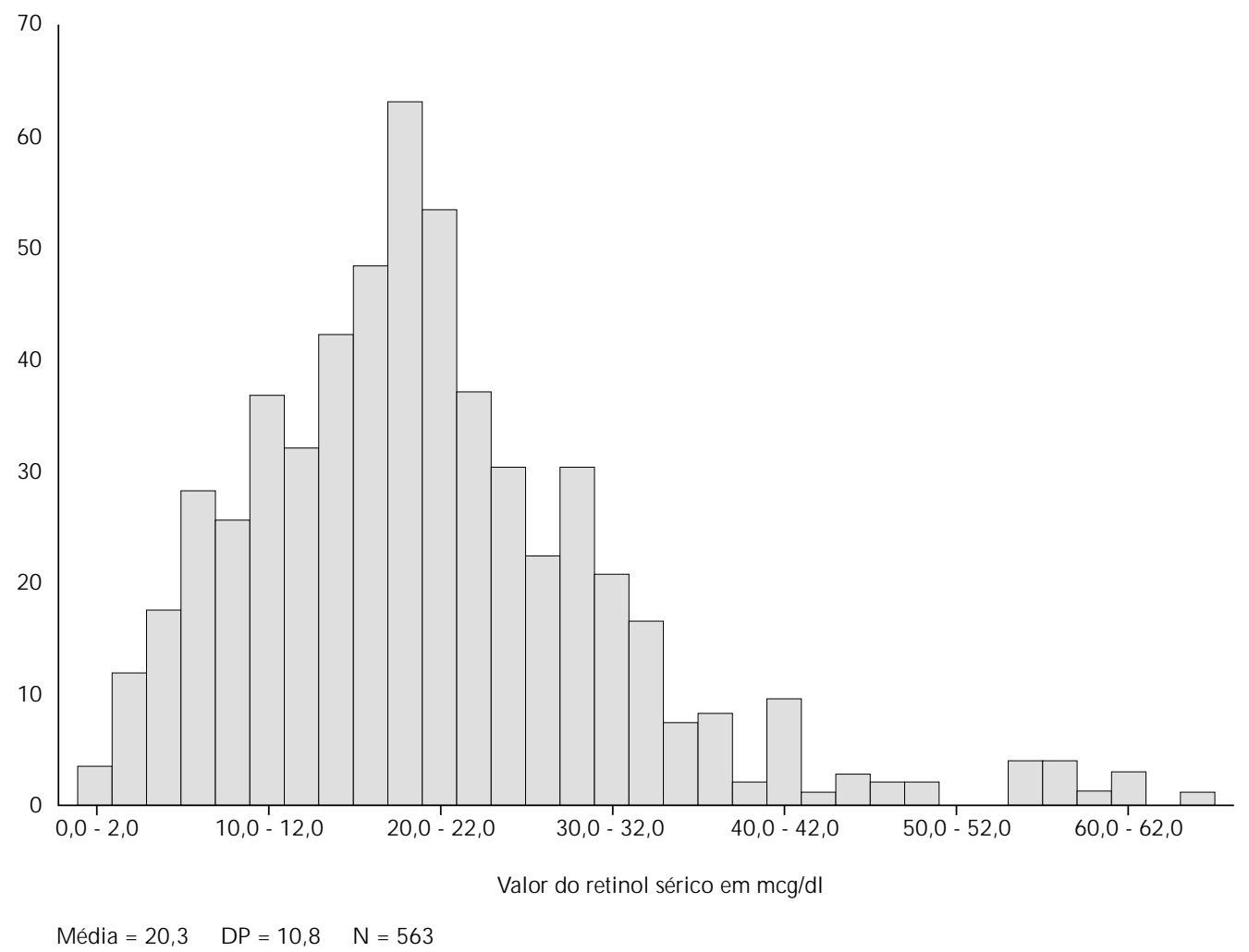

Figura 1 - Distribuição dos níveis de retinol sérico 


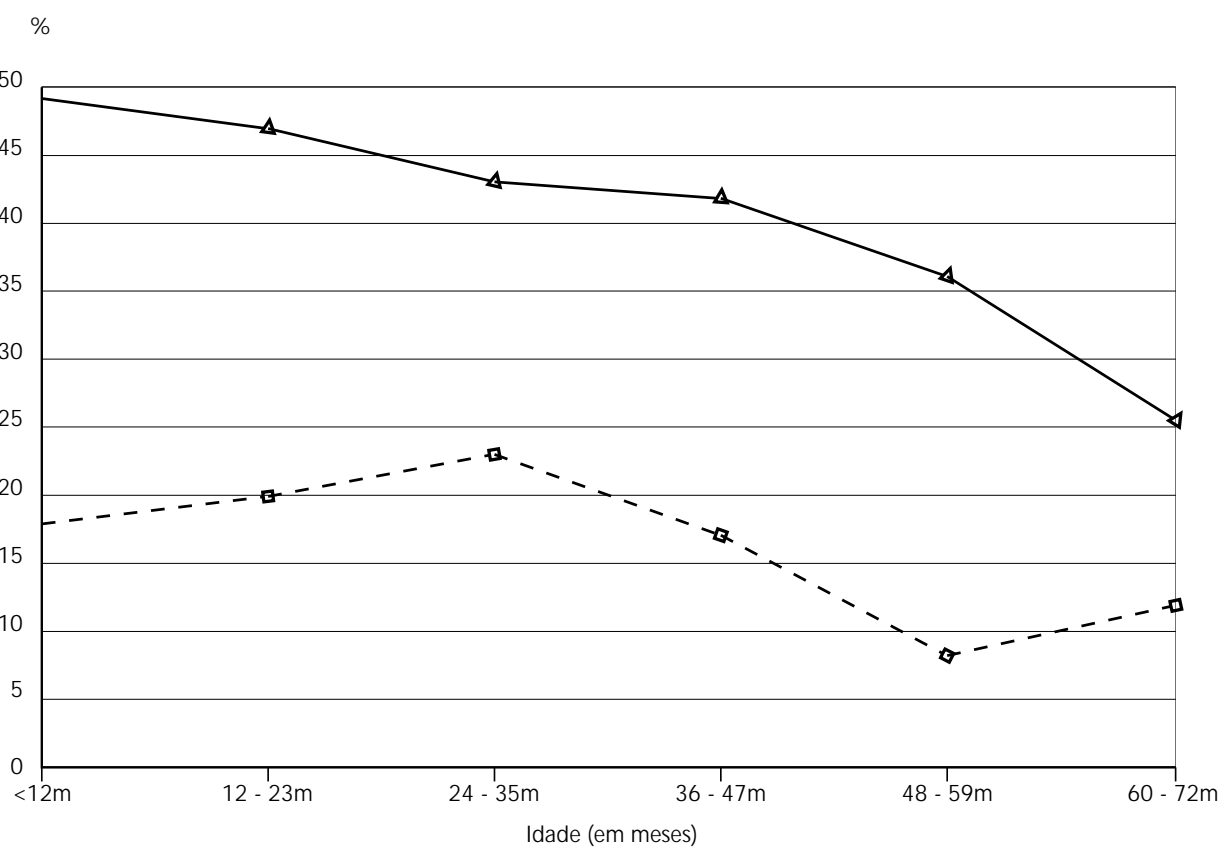

$$
\text { - - } \quad \text { - 10,0 - 19,9 }
$$$$
\Delta<10,0
$$

Figura 2 - Variação da prevalência de níveis de retinol sérico deficiente $(<10,0 \mu \mathrm{g} / \mathrm{dl}$ e baixo 10,0 - 19,9 $\mu \mathrm{g} / \mathrm{dl})$ com a idade em pré-escolares do sistema semi-árido da Bahia - 1989.

Tabela 2 - Níveis séricos de retinol, segundo a utilização de medicamentos com vitamina A em pré-escolares do semi-árido da Bahia - 1989.

\begin{tabular}{|c|c|c|c|}
\hline \multirow{2}{*}{$\begin{array}{l}\text { Utilização de medicamento com } \\
\text { vitamina A nos } 3 \mathrm{~m} \text {. precedentes }\end{array}$} & \multicolumn{2}{|c|}{ Níveis de retinol sérico* } & \multirow[b]{2}{*}{ Total } \\
\hline & $<10,0 \mu \mathrm{g} / \mathrm{dl}$ & $\approx 10,0 \mu \mathrm{g} / \mathrm{dl}$ & \\
\hline Sim & $\begin{array}{ll}2 & (2,4 \%)\end{array}$ & $26 \quad(5,7 \%)$ & $28 \quad(5,2 \%)$ \\
\hline Não & $81 \quad(97,6 \%)$ & $428(94,3 \%)$ & $509(94,8 \%)$ \\
\hline Total & $83(100,0 \%)$ & $454(100,0 \%)$ & 537 \\
\hline
\end{tabular}

$* p=0,166$ (unilateral) (Teste de probabilidade exata de Fisher)

Tabela 3 - Distribuição de retinol sérico deficiente, segundo a escolaridade das mães de pré-escolares do semi-árido da Bahia - 1989.

\begin{tabular}{|c|c|c|c|c|}
\hline \multirow[b]{2}{*}{ Escolaridade da mãe } & \multicolumn{2}{|c|}{ Retinol $<10,0 \mu \mathrm{g} / \mathrm{dl}$} & \multicolumn{2}{|c|}{ Retinol $\approx 10,0 \mu \mathrm{g} / \mathrm{dl}$} \\
\hline & $\overline{\mathrm{N}}$ & Prevalência* (\%) & $\bar{N}$ & Prevalência* (\%) \\
\hline Secundária & 1 & 3,2 & 30 & 96,8 \\
\hline Primária & 36 & 17,1 & 174 & 82,9 \\
\hline Alfabetizada & 9 & 9,6 & 85 & 90,4 \\
\hline Analfabeta & 38 & 17,3 & 182 & 82,7 \\
\hline Total & 84 & 15,1 & 471 & 84,9 \\
\hline
\end{tabular}

* $p=0,349$ (Teste para tendência)

Tabela 4 - Risco de retinol sérico deficiente, segundo a renda per capita das famílias de pré-escolares do semi-árido da Bahia - 1989.

\begin{tabular}{|c|c|c|c|}
\hline \multirow[b]{2}{*}{ Renda familiar per capita } & \multirow{2}{*}{$\begin{array}{l}\text { Prevalência de retinol sérico deficiente* } \\
\qquad(\%)\end{array}$} & \multicolumn{2}{|c|}{ Razão de prevalência } \\
\hline & & R.P. & [I.C.] \\
\hline$<1 / 4 \mathrm{SM}(\mathrm{N}=281)$ & 16,0 & 1,4 & {$[0,7-2,9]$} \\
\hline $\begin{array}{l}1 / 4 \text { a } 1 / 2 \text { SM }(N=181) \\
>1 / 2 \text { SM }(\mathrm{N}=72)\end{array}$ & $\begin{array}{l}16,0 \\
11,1\end{array}$ & $\begin{array}{l}1,4 \\
1,0\end{array}$ & {$[0,7-3,0]$} \\
\hline Total $(\mathrm{N}=534)$ & 15,4 & - & - \\
\hline
\end{tabular}


baixos registrou-se a prevalência de $48,9 \%$ nas crianças abaixo dos 12 meses a qual decresceu com o aumento da idade, até atingir $25,3 \%$ no grupo de 60 a 72 meses. A distribuição de retinol sérico deficiente, segundo o sexo da criança, apresentou resultados semelhantes entre meninos e meninas: $15,2 \%$ e $15,4 \%$, respectivamente $(\mathrm{p}=0,942)$.

Foi investigada a associação entre os níveis de retinol sérico e o uso de medicamentos com vitamina A nos 3 meses que antecederam a pesquisa (um possível fator de confundimento); os resultados na Tabela 2 mostram que 5,2\% das crianças haviam consumido medicação com altas doses desta vitamina, contudo não houve significância estatística $(\mathrm{p}=0,163)$.

Não houve evidência de que a distribuição de retinol sérico deficiente diferisse de acordo com a escolaridade materna $(\mathrm{p}=0,349)$; contudo, filhos de mães analfabetas mostraram a prevalência mais alta $(17,3 \%)$ (Tabela 3). Analisando esta distribuição, segundo a renda familiar per capita, encontrou-se a mesma prevalência de retinol deficiente para crianças de famílias com renda nos dois estratos mais baixos (Tabela 4); para a distribuição, como um todo, a diferença não foi estatisticamente significativa. Para cada nível de renda foi calculada a Razão de Prevalência (RP) e Intervalo de Confiança (IC) tendo-se como referência o grupo de renda mais elevado $(\mathrm{RP}=1)$. As razões de

Tabela 5 - Distribuição da freqüência de adequação dietética de vitamina A por categoria em pré-escolares do semi-árido da Bahia - 1989.

\begin{tabular}{lrc}
\hline Categoria de adequação* & $\mathrm{N}$ & Percentagem \\
\hline$<25,0$ & 212 & 34,4 \\
25,0 a 49,9 & 198 & 32,1 \\
50,0 a 74,9 & 106 & 7,2 \\
75,0 a 99,9 & 51 & 8,3 \\
$\approx 100,0$ & 49 & 8,0 \\
\hline Total & 616 & 100,0 \\
\hline
\end{tabular}

* Percentagem da recomendação da $\mathrm{FAO} / 0 \mathrm{M} \mathrm{S}^{12}$ prevalência encontradas incluem "1" dentro de seu intervalo de confiança, não sendo portanto significativas.

Os resultados de consumo alimentar de vitamina A proveniente do inquérito recordatório de $24 \mathrm{~h}$ estão apresentados na Tabela 5. Apenas 49 crianças (8\%) consumiram quantidades adequadas de retinol ou seus precursores; $66 \%$ ingeriam abaixo da metade e quase $35 \%$ delas não chegaram a ingerir um quarto da quantidade recomendada para sua faixa etária. Analisando-se a prevalência de retinol sérico deficiente segundo o consumo alimentar da vitamina (Tabela 6) parece haver uma diminuição na medida em que a adequação de consumo aumenta, porém esta não chegou a alcançar significância estatística $(\mathrm{p}=0,062)$.

\section{DISCUSSÃO E CONCLUSÕES}

Vários indicadores são atualmente empregados para detectar a carência de vitamina A: os clínicos (sinais e sintomas de xeroftalmia), os bioquímicos (níveis séricos e hepáticos de retinol, teste de Resposta Relativa (Relative Dose Response, RDR) e sua versão modificada, (Modified Relative Dose Response, m-RDR), o citológico (impressão conjuntival) e os dietéticos (inquéritos quantitativos e qualitativos $)^{21}$. $\mathrm{O}$ assunto tem merecido considerável atenção por parte da comunidade científica internacional ${ }^{36}$, pois os diversos indicadores não têm apresentado grau satisfatório de concordância. Uma das principais limitações na utilização do retinol sérico, como indicador, é o fato de que ele não reflete com fidelidade as reservas orgânicas (hepáticas) deste nutriente. Vários fatores contribuem para o rebaixamento dos níveis de retinol sérico, entre os quais destacam-se as infeções, que aumentam o seu desgaste ${ }^{6,13}$ e a desnutrição energético-protéica, que afeta a síntese da proteína de enlace de retinol (Retinol Binding Protein, RBP), proteína que tem uma meia vida bastante curta ${ }^{23}$. Estes e outros fatores

Tabela 6 - Prevalência de retinol deficiente, segundo a adequação de consumo diário de vitamina A dietética em préescolares do semi-árido da Bahia - 1989.

\begin{tabular}{lcccc}
\hline & \multicolumn{2}{c}{ Retinol $<10,0 \mu \mathrm{g} / \mathrm{dl}$} & \multicolumn{2}{c}{ Retinol $\approx 10,0 \mu \mathrm{g} / \mathrm{dl}$} \\
\cline { 2 - 5 } Categoria de adequação* & $\mathrm{N}$ & Prevalência** $(\%)$ & $\mathrm{N}$ & Prevalência** $(\%)$ \\
\hline$<25,0$ & 29 & 17,7 & 135 & 82,3 \\
25,0 a 49,9 & 26 & 17,1 & 126 & 82,9 \\
50,0 a 74,9 & 8 & 10,8 & 66 & 89,2 \\
75,0 a 99,9 & 3 & 8,1 & 34 & 91,9 \\
$\approx 100$ & 4 & 10,5 & 34 & 89,5 \\
\hline Total & 70 & 15,1 & 395 & 84,9 \\
\hline
\end{tabular}

* Percentagem da recomendação da $\mathrm{FAO} / \mathrm{O} \mathrm{M} \mathrm{S}^{12}$

** $p=0,062$ (Teste para tendência) 
interferem nos resultados de estudos que visam a determinar a sensibilidade e especificidade dos diferentes indicadores da carência de vitamina A. Por estas razões, tem sido freqüente a utilização de pelo menos dois indicadores, nos estudos epidemiológicos dessa carência.

A carência de vitamina A deve ser considerada como importante problema de saúde na população estudada, tanto pela alta prevalência de níveis inadequados de retinol em todos os municípios (superando o critério da Organização Mundial de Saúde (OMS) para problema de saúde pública severo), como também pela dimensão da inadequação dietética.

Os dados de consumo alimentar do presente estudo não podem ser diretamente comparados com os resultados do inquérito nacional de 1975-76 $(\text { ENDEF })^{16}$, que mediu o consumo familiar. Contudo, a prevalência encontrada foi da mesma ordem de grandeza nos dois estudos $(66 \%$ das crianças no presente estudo com consumo abaixo de $50 \%$ da recomendação contra $53 \%$ das famílias com crianças menores de cinco anos do Nordeste urbano no ENDEF, com o mesmo nível de inadequação ${ }^{15}$. Estudos no Estado da Paraíba permitiram lançar a hipótese de que o desmame precoce poderia explicar tanto a distribuição geográfica como a aparente história natural da doença nos casos de xeroftalmia e cegueira nutricional por carência de vitamina A, que foram registrados no início da década de $80^{1,10}$. Em outros países onde a xeroftalmia ocorre em maior prevalência como em Malawi, esta hipótese pôde ser testada: encontrou-se que crianças com xeroftalmia começaram a receber suplemento alimentar mais cedo (mingau) e sofreram desmame completo mais precoce do que os controles ${ }^{34}$.

Em que pese o fato de dois indicadores, consumo alimentar e níveis de retinol sérico, serem suficientes para se considerar a carência de vitamina A como problema de saúde pública severo na área, é de se registrar que nenhum caso de sinais clínicos e/ou sintomas de xeroftalmia foi detectado no presente

\section{REFERÊNCIAS BIBLIOGRÁFICAS}

1. ARAUJO, Rosania L. et al. Diagnóstico e evolução de casos de ceratomalácia e xeroftalmia. J. Pediatr. Rio J., 57: 419-24, 1984.

2. ARAUJO, Rocyval L. Situação alimentar e nutricional do Brasil. Brasília, Editora Gráfica Tipogresso, 1989.

3. BARRETO, M.L. et al. Effect of vitamin A. supplementation on diarrhoea and acute lower respiratory infections in preschool children in Northeast Brazil. Lancet, 344: 228-31, 1994. estudo. A prevalência proposta pela OMS para considerar problema de saúde pública, baseado nos indicadores clínicos de carência de vitamina $\mathrm{A}(0,5 \%$ para Manchas de Bitot e 0,01\% para xerose corneal por exemplo), é muito menor que a prevalência de níveis séricos de retinol (20\% abaixo de $20 \mu \mathrm{g} / \mathrm{dl})$, refletindo o fato de que mesmo onde a hipovitaminose $\mathrm{A}$ é endêmica, os sinais clínicos não são muito freqüentes. Desta forma, a amostra estudada, de 754 pré-escolares, não é de tamanho suficiente para permitir afirmar com alguma segurança que esses sinais realmente não ocorrem. E em hospitais pediátricos em Salvador, capital do Estado da Bahia, casos esporádicos de xeroftalmia e ceratomalácia têm sido registrados em crianças desnutridas e com infecções graves*.

Na população incluída no presente estudo, a hipovitaminose A não mostrou associação com educação materna nem com renda familiar per capita. Contudo em relação à desnutrição energético-protéica estudada na mesma população, tanto altura/idade como peso/idade mostraram forte associação com renda, e o risco encontrado foi duas vezes superior nas crianças de famílias no menor estrato de renda ${ }^{32}$. Esta aparente dissociação das carências de micronutrientes com importantes variáveis socio-econômicas merece ser melhor investigada e pode ter implicações programáticas importantes.

\section{AGRADECIMENTOS}

Ao prof. Hernando Flores do Departamento de Nutrição da Universidade Federal de Pernambuco, pelo treinamento oferecido e pelo fornecimento do padrão de vitamina $A$; às nutricionistas Claudia Stefany, Gilca M.C. Quaglia, Lilian Ramos, Rita Ribeiro, à médica Celia M. Baqueiro, às alunas de Nutrição pela colaboração na coleta dos dados e à nutricionista Lilian Cupari, da Escola Paulista de Medicina, pela cessão do Programa de Apoio à Decisão em Nutrição.

4. BEATON, G.H. et al. Effectiveness of vitamin A supplementation in the control of young child morbidity and mortality in developing countries; final report to CIDA. Toronto, University of Toronto, 1993.

5. BESSEY, O.A. et al. The determination of vitamin A and carotene in small quantities of blood serum. J. Biol. Chem., 166: 177,1946

* Santos, L.M.P. - Dados inéditos. 
6. CAMPOS, F.A.C.S. et al. Effect of an infection on vitamin A status of children as measured by the relative dose response (RDR). Am. J. Clin. Nutr., 46: 91-4, 1987.

7. CASTRO, J. Geografia da fome. $8^{\text {a }}$ ed. Rio de Janeiro. Editora Arantes, 1963.

8. CALVALCANTI, L.R. Hemeralopia, manifestação da avitaminose A observada entre os flagelados da seca do Nordeste. Arq. Bras. Neuro. Psiquiatr., 17: 16, 1934.

9. CUNHA, E. Os sertões. Rio de Janeiro, Livraria Francisco Alves, 1938.

10. DRICOT D'ANS, C. et al. Geographic distribution of xerophthalmia in the state of Paraiba, Northeast Brazil. Ecol.Food Nutr., 22: 131-8, 1988.

11. FAO/WHO. Requirements of vitamin A, iron, folate and vitamin B12; report of a joint $\mathrm{FAO} / \mathrm{WHO}$ expert consultation. Rome, 1988. (FAO Food and Nutrition Series 23).

12. FAWIS, W.W. et al. Vitamin A supplementation and child mortality; a meta-analysis. JAMA, 269: 898-903, 1993.

13. FILTEAU, S. M. et al. Influence of morbidity on serum retinol of children in a community-based study in northern Ghana. Am. J. Clin. Nutr., 58: 192-7, 1993 ,

14. FLORES, H. \& ARAUJO, C.R.C. Liver levels of retinol in unselected necropsy specimens: a prevalence survey of vitamin A deficiency in Recife, Brazil. Am. J.Clin. Nutr., 40: 146-52, 1984.

15. FUNDAÇÃO IBGE. Perfil estatístico de crianças e mães no Brasil: aspectos nutricionais 1974-75. Rio de Janeiro, 1982.

16. FUNDAÇÃO IBGE. Tabela de composição de alimentos. Rio de Janeiro, 1977 (Estudo Nacional de Despesa Familiar).

17. GAMA LOBO, M. Da ophtalmia braziliana. An.Brazil. Med., 30: 16, 1865.

18. GHANA VAST STUDY TEAM. Vitamin A. supplementation in northern Ghana: effects on clinic attendances, hospital admissions, and child mortality. Lancet, 342: 7-12, 1993.

19. GLAZIOU, P.I. \& MACKERRAS, D.E.M. Vitamin A supplementation and infectious disease: a meta-analysis. BMJ, 306: 366-70, 1993.

20. IVACG. Biochemical methodology for the assessment of vitamin A status. Washington, D.C., Nutrition Foundation, 1982.

21. IVACG. Guidelines for the development of a simplified dietary assessment to identify groups at risk for inadequate intake of vitamin A. Washington, D.C., Nutrition Foundation, 1989.
22. LEÃO, J.V. A desnutrição no meio escolar de Fortaleza. Bol. Inst. Pueric. Univ. Brasil, 15: 172-7, 1958.

23. LEE, R. D. \& Nieman, D. C. Nutritional assessment. London, England WCB, 1993.

24. MARIATH, J.G.R. et al. Vitamin A activity of buriti (Mauritia vinifera Mart) ans its effectiveness imn the treatment and prevention of xerophthalmia. Am. J. Clin. Nutr., 49: 849-53, 1989.

25. OLSON, J.A. The biological role of vitamin A in maintaining ephitelial tissues. Is. J. Med. Sci, 8: 1170-8, 1972.

26. OLSON, J.A. Liver vitamin A reserves of neonates, preschool children and adults dying of various causes in Salvador Brazil. Arch. Latinoam. Nutr. 23: 521-45, 1979.

27. ROSS, A.C. Vitamin A status: relation to immunity and the antibody response. Proc.Soc.Exp.Biol.Med., 200: 303-30, 1992.

28. SANTOS, L.M.P. et al. Estudo epidemiológico da xeroftalmia na Paraíba. Rev. Bras. Med., 40: 419-25, 1993.

29. SANTOS, L.M.P. et al. Xerophthalmia in the state of Paraíba, northeast Brazil: clinical findings. Am. J. Clin. Nutr., 38: 139-44, 1983.

30. SANTOS, L.M.P. et al. Vitamin A status in Brazil. Am. J. Clin. Nutr., 45: 1548, 1987.

31. SANTOS, L.M.P. \& CRUZ, T. Nutrition in Brazil: current situation and intervention programs. IDF Bull., 35: 64-6, 1990.

32. SANTOS, L.M.P. et al. Situação alimentar e nutricional de pré-escolares no semi-árido da Bahia (Brasil) I - Avaliação antropométrica. Rev. Saúde Pública, 29: 463-71, 1995.

33. VARELA, R. M. et al. Hypovitaminosis A in the sugar cane zone of Southern Pernambuco State, Northeast Brazil. Am. J. Clin. Nutr., 25: 800-4, 1972.

34. WEST, K.P. et al. Breast-feeding weaning patterns and the risk of xerophthalmia in Southern Malawi. Am. J. Clin. Nutr., 44: 690-7, 1986.

35. WILLET, W. Nutritional epidemiology. New York, Oxford University Press., 1990.

36. WORLD HEALTH ORGANIZATION/UNICEF. Indicators for assessing vitamin A deficiency and their application in monitoring and evaluating intervention programmes; report of a joint WHO/UNICEF consultation. Geneva, 1994.

37. WORLD HEALTH ORGANIZATION. Joint WHO / UNICEF / USAID / HKI / IVACG meeting. Control of vitamin A deficiency and xerophthalmia. Jakarta, 1980. Report. Geneva, 1982. (WHO - Technical Report Series, 672). 